\title{
AUGUSTUS
}

\section{O ESTADO DE EXCEÇÃO NAS FAVELAS: PERSPECTIVAS BIOPOLÍTICAS A PARTIR DA PANDEMIA DO COVID-19}

\author{
Marcus Alexandre de Pádua Cavalcanti Bastos \\ Doutor em Educação em Ciências e Saúde pela Universidade Federal do Rio de Janeiro \\ (UFRJ), Rio de Janeiro, RJ, Brasil \\ marcus_nathan120@hotmail.com \\ Eliane Cristina Tenório Cavalcanti \\ Doutoranda em Educação em Ciências e Saúde pela Universidade Federal do Rio de Janeiro \\ (UFRJ), Rio de Janeiro, RJ, Brasil \\ eliane.cavalcanti@hotmail.com.br \\ Rosane Ferreira da Silva \\ Mestranda em Humanidades, Cultura e Artes pela Universidade do Grande Rio \\ (Unigranrio), Rio de Janeiro, RJ, Brasil \\ rosafisio@gmail.com \\ Elizabeth Almenara da Silva \\ Médica Veterinária pela Universidade do Grande Rio (Unigranrio), \\ Rio de Janeiro, RJ, Brasil \\ elizabeth_veterinária@hotmail.com \\ Nathan da Costa Cavalcanti Bastos \\ Bacharelando em Farmácia pela Universidade Estácio de Sá, Rio de Janeiro, RJ, Brasil \\ nathan-psytrance@hotmail.com \\ Allain Cristian Tenório Cavalcanti \\ Bacharelando em Pedagogia pela Universidade Estácio de Sá, Rio de Janeiro, RJ, Brasil \\ allain_cristian@hotmail.com
}

\section{RESUMO}

A expansão do novo coronavírus - COVID-19, classificado como pandemia pela Organização Mundial da Saúde (OMS), vem causando insegurança e muita incerteza por todo o mundo. $\mathrm{O}$ crescimento exponencial fez com que o vírus atingisse também as comunidades mais pobres. Esses são espaços com alta densidade demográfica, habitações precárias com poucos cômodos e que possuem pouca ventilação. Também faltam equipamentos de saúde, não há rede de esgoto, saneamento básico e água potável. Todos esses elementos apontam para uma situação de abandono por parte do Estado em que moradores passam a ser incluídos no seio de uma exceção, uma zona de indistinção em que a vida se torna apenas biológica, uma existência destituída de qualquer valor, mera vida. Essa situação de 
abandono se agrava ainda mais no contexto de uma pandemia e evidencia a existência de uma biopolítica baseada na exclusão dessas populações. Desse modo, o presente artigo pretende partir das considerações sobre biopolítica, de Michel Foucault, e de conceitos apresentados por Giorgio Agamben, como vida nua, homo sacer e poder soberano para debater de que maneira um cenário pandêmico pode aprofundar ainda mais as desigualdades nas favelas.

Palavras-chave: Biopolítica. Vida nua. Estado de exceção.

\title{
THE STATE OF EXCEPTION IN THE SLUMPS BIOPOLITICAL PERSPECTIVES FROM THE COVID- 19 PANDEMIC
}

\begin{abstract}
The expansion of the new coronavirus - COVID-19, classified as a pandemic by the World Health Organization (WHO), has caused insecurity and much uncertainty worldwide. Exponential growth has caused the virus to reach the poorest communities as well. These are spaces with a high demographic density, precarious housing with few rooms and poor ventilation. Health equipment is also lacking, there is no sewage network, basic sanitation and drinking water. All of these elements point to a situation of abandonment on the part of the State in which residents are included in the midst of an exception, a zone of indistinction in which life becomes only biological life, an existence devoid of any value, mere life. This situation of abandonment is even worse in the context of a pandemic and shows the existence of a biopolitics based on the exclusion of these populations. Thus, the present article intends to start from Michel Foucault's biopolitical considerations and from concepts presented by Giorgio Agamben, such as naked life, homo sacer and sovereign power to debate how a pandemic scenario can deepen inequalities in the favelas.
\end{abstract}

Keyword: Biopolitics. Naked life. State of exception. 


\section{INTRODUÇÃO}

No dia 11 de março de 2020, a Organização Mundial da Saúde (OMS) declarou que a expansão do novo coronavírus, que causa a doença denominada COVID-19, já se configurava como uma pandemia. (GIRARDI, 2020). Os primeiros meses de 2020 foram marcados pelo rápido aumento do número de contaminados em todo o mundo. Em um primeiro momento, a contaminação por um vírus em escala global parece um fenômeno democrático, ou seja, que não distingue quem atinge. Entretanto, a crise causada pela pandemia tem colocado em evidência as profundas desigualdades socioeconômicas e territoriais.

A pandemia chegou ao Brasil e encontrou um país já bastante fragilizado, sob forte política de austeridade e desmonte da proteção social. Exemplo disso é o congelamento dos gastos públicos com saúde e educação por 20 anos, decretados pela Emenda Constitucional 95 e a retirada de direitos trabalhistas e previdenciários. Há o subfinanciamento crônico do SUS, os ataques às universidades com cortes de bolsas de pesquisa, mesmo durante a crise de coronavírus, prática essa que aponta a desvalorização da pesquisa científica.

Todas essas medidas atingem grande parte da população brasileira, principalmente aqueles que moram de forma precária em favelas e comunidades sem saneamento básico, com pouco ou sem nenhum acesso à água encanada que garanta condições mínimas de prevenção e proteção. Muitos dos habitantes desses locais residem em assentamentos precários: moradias com um ou dois cômodos, pouca ventilação, frequentemente compartilhadas por um número grande de familiares. Nessas regiões, os serviços públicos de maneira geral não são prestados como deveriam. (ROLNIK, 1999).

Para Rolnik (1999), são inúmeros os desafios em decorrência da vulnerabilidade que marca esses territórios. A autora enfatiza que

\footnotetext{
Os territórios excluídos constituíram-se à revelia da presença do Estado - ou de qualquer esfera pública - e, portanto, desenvolvem-se sem qualquer controle ou assistência. Serviços públicos, quando existentes, são mais precários do que em outras partes das cidades; trabalhar nessas áreas muitas vezes é visto pelos funcionários públicos como "castigo". Mais do que isso, viver permanentemente sob uma condição de privação de necessidades ambientais básicas faz os habitantes se sentirem como se suas vidas tivessem pouco valor. (ROLNIK, 1999, p. 107).
} 
Percebemos uma verdadeira precarização da vida dos moradores das favelas, que refletem exatamente a existência de uma biopolítica em que a inclusão se confunde com a exclusão, uma vez que os sujeitos que habitam essas localidades são destituídos de vida plena. Esses sujeitos são incluídos no seio de uma exceção, encarnando assim, uma vida destituída de humanidade, uma mera vida biológica. Essa situação de abandono se agrava ainda mais no contexto de uma pandemia.

Desse modo, o presente artigo pretende partir das considerações sobre biopolítica, de Michel Foucault (2005), e de conceitos apresentados por Giorgio Agamben (2004), como vida nua, homo sacer e poder soberano debater de que maneira um cenário pandêmico pode aprofundar as desigualdades nas favelas.

\section{DO PODER SOBERANO A BIOPOLÍTICA}

Por muito tempo, explica Foucault (2005), o poder soberano possuiu como uma das principais características o direito de vida e de morte, ele consiste fundamentalmente em "fazer morrer e deixar viver". Contudo, este não era utilizado pelo soberano com relação aos seus súditos em termos absolutos ou de maneira incondicional, mas exclusivamente em situações em que o soberano tivesse sua própria existência ameaçada. Desse modo, este direito era condicionado à defesa do soberano e também à sua sobrevivência, era o direito de causar a morte ou de deixar viver.

Com desenvolvimento da sociedade moderna e das novas relações de produção capitalistas foi necessário criar outras tecnologias de poder. O poder disciplinar e a biopolítica da espécie humana surgem no decorrer de segunda metade do século XVII e no decorrer do século XVIII, respectivamente, como instrumentos de formatação e normalização dos indivíduos e das populações, uma espécie de ajustamento dos indivíduos às novas relações de produção que estavam em pleno desenvolvimento. (FOUCAULT, 2005).

A primeira tecnologia se centrou no corpo-máquina, que teve como finalidade o seu adestramento, a ampliação de suas aptidões, a utilização de suas forças visando o crescimento de sua utilidade. Essa tecnologia tem implicações importantes em sua concepção de poder: refere-se aos mecanismos - dentre os quais a vigilância ininterrupta - 
com os quais o poder domestica os corpos e mentes, ao mesmo tempo em que produz um saber que intensifica o controle sobre os indivíduos a partir de um exercício crescente de individualização. A domesticação dos corpos se dá através de sua submissão a um exercício disciplinado, repetitivo e controlado. Tal controle implica em um corpo de saberes normatizados que vão dizer quem esse sujeito é e o lugar que ocupa dentre um conjunto de tipos classificáveis em torno da norma social. (DREYFUSS; RABINOW, 2006).

De acordo com Dreyfuss e Rabinow (2006) o poder disciplinar é uma tecnologia de poder que opera em pontos diversos do tecido social. Os autores apontam que

A tecnologia disciplinar foi desenvolvida e aperfeiçoada nas oficinas, quartéis, prisões e hospitais; em cada um desses locais o objetivo geral foi o "crescimento paralelo da utilidade e docilidade" dos indivíduos e do conjunto da população. As técnicas para disciplinar os corpos foram aplicadas principalmente entre as classes trabalhadoras e subproletariado, embora não exclusivamente, pois elas também operaram em universidades e escolas. (DREYFUSS; RABINOW 2006, p. 135).

A segunda forma de exercer o poder sobre a vida, a biopolítica, trata de questões coletivas, como nascimento, mortalidade, expectativa de vida, nível de saúde, longevidade. Tais processos são assumidos por meio de uma série de intervenções e controles reguladores. A biopolítica seria caracterizada pelo imperativo de "fazer viver", ou seja, são técnicas de controle da população que tem por objetivo maximizar a existência. (DREYFUSS; RABINOW, 2006).

Foucault (2005 p. 293) acrescenta que

\begin{abstract}
Nos mecanismos implantados pela biopolítica, vai se tratar, sobretudo, é claro, de previsões, de estimativas estatísticas, de medições globais; vai se tratar, igualmente, não de modificar tal fenômeno em especial, não tanto tal indivíduo, na medida em que é indivíduo, mas, essencialmente, de intervir no nível daquilo que são as determinações desses fenômenos gerais, desses fenômenos no que eles têm de global. Vai ser preciso modificar, baixar a morbidade; vai ser preciso encompridar a vida; vai ser preciso estimular a natalidade. E trata-se sobretudo de estabelecer mecanismos reguladores que, nessa população global com seu campo aleatório, vão poder fixar um equilíbrio, manter uma média, estabelecer uma espécie de homeóstase, assegurar compensações; em suma, de instalar mecanismos de previdência em torno desse aleatório que é inerente a uma população de seres vivos, de otimizar, se vocês preferirem, um estado de vida: mecanismos, como vocês vêem, como os mecanismos disciplinares, destinados em suma a maximizar forças e a extraí-las, mas que passam por caminhos inteiramente diferentes.
\end{abstract}


Os fenômenos que passam a ser levados em consideração, aqui, são os coletivos, ou seja, aqueles "que só aparecem com seus efeitos econômicos e políticos, que só se tornam pertinentes no nível da massa, o que significa dizer que a biopolítica vai se dirigir, em suma, aos acontecimentos aleatórios que ocorrem numa população considerada em sua duração". (FOUCAULT, 2005, p. 206).

Disto decorre a surgimento das tecnologias políticas que, a partir de então, serão investidas sobre a vida, sobre a totalidade dos indivíduos reunidos em sociedade. A vida de cada pessoa passa a ser objeto de controle, como também a vida de todas as pessoas. Essa apropriação do que há de biológico na vida não se dá por acaso, mas sim para que essas dimensões possam ser apropriadas por meio de cálculos e, ao sofrerem a incidência de mecanismos de controle. (FOUCAULT, 2005).

Foucault (2005, p. 134) afirma que

Se pudéssemos chamar de "bio-história" as pressões por meio das quais os movimentos da vida e os processos da história interferem entre si, deveríamos falar de "biopolítica" para designar o que faz com que a vida e seus mecanismos entrem no domínio dos cálculos explícitos, e faz do poder-saber um agente de transformação da vida humana.

É importante destacar que, para Foucault (2005, p. 183), o poder nunca é uno, pois não se trata de um "fenômeno de dominação maciço e homogêneo de um indivíduo sobre os outros, de um grupo sobre os outros, de uma classe sobre as outras".

Para o autor, o poder deve ser concebido de forma plural, pois na verdade seriam diferentes círculos de poder, uma vez que "o poder deve ser analisado como algo que circula, ou melhor, como algo que só funciona em cadeia. Nunca está localizado aqui ou ali, nunca está nas mãos de alguns, nunca é apropriado como uma riqueza ou um bem. O poder funciona e se exerce em rede". (FOUCAULT, 2005, p. 183).

Apesar de Foucault (2005) ter sido o primeiro a elaborar, com a biopolítica, uma nova concepção de poder e a identificar a inter-relação entre biopolítica e modernidade, muitos teóricos aprofundaram o tema e lhe conferiram novas perspectivas como é o caso de Giorgio Agamben (2004), que será tratado no tópico a seguir. 


\section{A BIOPOLÍTICA E A GESTÃO DA VIDA NUA HUMANA - A FIGURA DO HOMO SACER}

Trabalhando a partir das lições de Foucault (2005), Agamben (2004) buscou abordar uma nova dimensão da biopolítica. Para o autor, a biopolítica não é conseqüência de uma transformação do poder soberano, "mas o próprio aporte oriundo do poder soberano. Ao situar a vida biológica no centro de seus cálculos, o Estado moderno não faz outra coisa além de tornar a dar luz ao vínculo secreto que une o poder com a vida nua." (AGAMBEN, 2004, p. 16).

Por meio das análises que fazem parte de seu livro Homo sacer - o poder soberano e a vida nua, Agamben (2004) apresenta o que ele considera o ponto oculto no qual confluem o sistema jurídico-institucional e o sistema biopolítico do poder. Entre as questões defendidas nesta obra, está a ideia de que essas duas análises não devem se separar e a afirmação de que as implicações daquilo que o autor chama de "vida nua" - biológica - na esfera política compõem o núcleo originário, mesmo que velado, do poder soberano.

Agamben (2004) recorre a uma figura do direito romano arcaico para assinalar como soberania e vida nua já se implicavam mutuamente, muito antes da modernidade. No direito romano arcaico, o homo sacer era o titular da vida nua - vida desqualificada, pois sua existência era excluída da pólis e do direito. Essa condição de exclusão impossibilitava o excluído de ser sacrificado aos deuses. Entretanto, ele poderia ser morto por qualquer indivíduo, sem que para isso houvesse punição. Ao se reportar à figura do homo sacer, Agamben (2004, p. 90) esclarece que aquilo que defina essa condição:

\footnotetext{
Não é tanto a pretensa ambivalência originária da sacralidade que the é inerente, quanto, sobretudo, o caráter particular da dupla exclusão em que se encontra preso e da violência à qual se encontra exposto. Esta violência a morte insancionável que qualquer um pode cometer em relação a ele não é classificável nem como sacrifício e nem como homicídio, nem como execução de uma condenação e nem como sacrilégio. Subtraindo-se às formas sancionadas dos direitos humanos e divino, ela abre uma esfera do agir humano que não é a do sacrumfaceree nem a da ação profana.
}

O homo sacer é uma figura desprovida de direitos, um ser excluído da sociedade que pode ser morto impunemente, mas não pode jamais ser sacrificado aos deuses. A figura do homo sacer é utilizada por Agamben (2004) para retratar o que o autor chama de vida 
nua, ou seja, uma vida desqualificada, destituída de direitos, uma vida que não merece ser vivida.

Entre os gregos, explica Agamben (2004), havia duas palavras para designar a vida: a palavra zoé, o simples ato de viver, aquilo que os homens dividem com os animais e a bíos ou vida formalizada de um grupo ou indivíduo. “Ora, o homo sacer é uma zoé (vida natural) diretamente transformada em bíos (vida politizada), desenhando o campo moderno da política: a indissociabilidade da vida nua e da política." (AGAMBEN, 2004, p. 09).

Agamben (2004, p. 12) aponta que

\begin{abstract}
O ingresso da zoé na esfera da pólis, a politização da vida nua como tal constitui o evento decisivo da modernidade, que assinala uma transformação radical das categorias político-filosóficas do pensamento clássico. [...] Somente em um horizonte biopolítico, de fato, será possível decidir se as categorias sobre cujas oposições fundou-se a política moderna (direita/esquerda; privado/público; absolutismo/democracia etc.), e que se foram progressivamente esfumando a ponto de entrarem hoje numa verdadeira e própria zona de indiscernibilidade, deverão ser definitivamente abandonadas ou poderão eventualmente reencontrar o significado que naquele próprio horizonte haviam perdido.
\end{abstract}

Com o homo sacer, a vida humana se inclui no ordenamento jurídico unicamente sob a forma de sua exclusão. A inclusão da vida por meio de sua exclusão faz com que participe de um estado de exceção ${ }^{9}$. O estado de exceção, no qual a vida nua era, ao mesmo tempo, excluída da ordem jurídica e nela contida, esse é o fundamento oculto sobre o qual repousava todo o sistema político. (AGAMBEN, 2002).

No momento em que as fronteiras do estado de exceção se diluem e se fazem indeterminadas, a vida nua, específica, que ali ocupava fica liberada em toda parte e passa a ser ao mesmo tempo o sujeito e o objeto do ordenamento político e de seus conflitos, o espaço único tanto da organização do poder do estado como da emancipação dele (AGAMBEN, 2002).

\footnotetext{
${ }^{9}$ A teorização agambeniana (2002) acerca do estado de exceção parte da polêmica e amplamente conhecida formulação de Carl Schmitt, que introduz sua obra Teologia política com a seguinte definição: "Soberano é aquele que decide do estado de exceção". Nesse sentido, o soberano "está na margem da ordem jurídica normalmente em vigor, estando ao mesmo tempo submetido a ela, pois a ele incumbe decidir se a Constituição deve ser suspensa em sua totalidade". Logo, a decisão do soberano pela exceção "se libera de toda obrigação normativa e torna-se absoluta em sentido próprio. No caso de exceção, o Estado suspende o direito em virtude de um direito de autoconservação." (AGAMBEN, 2002, p. 22).
} 
Na modernidade, sugere Agamben (2004) o princípio da sacralidade da vida se emancipou por completo da noção de sacrifício. O significado do termo sagrado em nossa cultura prolonga a história semântica do homo sacer e não a do sacrifício religioso. A vida cada vez mais se expõe a uma violência sem precedentes, mas que se manifesta nas formas mais profanas e banais.

Nos dois casos, estas transposições se produziram em contextos onde a política já havia se transformado em biopolítica e nos quais o que estava em jogo consistia já exclusivamente em determinar que forma de organização resultaria mais eficaz para assegurar o cuidado, o controle e o desfrute da vida nua. A diferença está apenas no fato de que uma mesma reivindicação da vida nua conduz, nas democracias burguesas, ao primado do privado sobre o público e das liberdades individuais sobre as obrigações coletivas. (AGAMBEN, 2004).

Cabe destacar que o aspecto central da abordagem empreendida por Agamben (2004), no que concerne à biopolítica, é a identificação de uma estrutura jurídica, que existe desde a gênese da experiência política ocidental, relacionando direito e vida, ou seja, a existência de um poder soberano e de um estado de exceção que se torna regra na modernidade, capaz de tomar a vida em seu aspecto mais elementar: a nudez da vida sem qualquer direito político, ou um corpo biológico "à mercê" (abandonado) do poder soberano.

Portanto, entre a esfera da vida nua e a esfera do jurídico-institucional existe um vínculo que frequentemente permanece oculto. Mas esses dois âmbitos de análise não podem ser separados, haja vista que "a implicação da vida nua na esfera política constitui o núcleo originário - ainda que encoberto - do poder soberano." (AGAMBEN, 2004, p. 14).

Parece que existem inúmeras situações que exemplificam esse conceito de "vida nua" no mundo contemporâneo. Pode-se evidenciar esse cenário atual com um exemplo que parece ser bastante pertinente nos dias de hoje: o morador da favela, ou seja, um ser humano privado de sua bios. 


\section{ATUAÇÃO BIOPOLÍTICA NAS FAVELAS}

As favelas ${ }^{10}$ representam uma parte considerável do Brasil onde os direitos humanos são ignorados, onde a qualidade de vida é precária e a população se ocupa diariamente em garantir sua sobrevivência, sendo privada do direito de exercer uma vida qualificada. A favela é um local onde há ausência de Estado, de lei, de cidadania, de serviços públicos e de organização. Ela é também um território específico da pobreza, cujos moradores não têm as mínimas condições de cumprirem as medidas de higiene, alimentação saudável. (FARIAS, 2008).

As populações dessas áreas sobrevivem em locais pequenos e sem ventilação, propícios à disseminação do vírus, podendo atingir um nível de contaminação em proporção inimaginável. As condições de habitação (casas podendo ter apenas um cômodo, por exemplo), de saneamento, acesso à água, coleta de lixo e de transporte compõem o cenário preocupante que se agrava durante a pandemia do Covid-19. No Brasil, são 35 milhões de pessoas vivendo sem acesso à água tratada e 100 milhões sem esgoto. (Sistema Nacional de Informações sobre Saneamento, 2018). Anualmente, são 300 mil internações por doenças causadas por falta de saneamento, como a hepatite A e a leptospirose. (BARRUCHO, 2020).

Alfano et al (2020) alerta que é impensável que alguém contaminado em um cômodo em uma favela não se torne agente de contaminação em potencial, ao mesmo tempo em que uma residência precária não é um ambiente possível de garantir recuperação de ninguém.

Ling (2020) cita Ana Luísa Gomes, doutora em epidemiologia da Fiocruz, "Se a COVID-19 se espalhar dentro de uma comunidade, vai ser muito rápido o contágio daquela população." O autor indica que

\footnotetext{
Isso ocorre dado que a aglomeração em comunidades informais é ainda maior: as pessoas ficam muito mais próximas, unidades habitacionais são menores e muitas vezes não conseguem, por restrição de espaço físico, seguir as medidas recomendadas pelo Ministério da Saúde em caso de contaminação do vírus, de isolamento em cômodo separado da casa. (LING, 2020).
}

\footnotetext{
${ }^{10} \mathrm{O}$ Instituto Brasileiro de Geografia e Estatística (IBGE) convencionou denominar as favelas em aglomerados subnormais, caracterizando-as por "grupos de mais de 50 unidades habitacionais dispostas de modo 'desordenado e denso', sobre solo que pertence a terceiros, e 'carente de serviços públicos essenciais'. Opõemse aos setores normais que, por exclusão, constituem a cidade formal." (RIO DE JANEIRO, 2010, p. 1).
} 
Segundo o IBGE (2010), há no Brasil mais de 15 milhões de famílias - cerca de 60 milhões de pessoas estão em favelas, ocupações e loteamentos, em situação de risco social e em condições miseráveis de habitação. Segundo o IBGE (2010), dados apontam que existem 6.329 favelas no País. Nelas está a maior parte dos cerca de 13,5 milhões de famílias que vivem na extrema pobreza. Se de um lado o isolamento social recomendado pela Organização Mundial da Saúde (OMS) tem sido a maneira mais eficaz de diminuir - ou mesmo evitar a contaminação - e ainda não causar um colapso do sistema de saúde, de outro lado existem a preocupação sobre como estabelecer medidas para conter a disseminação do vírus entre as comunidades mais pobres, onde os moradores e vizinhos estão muito mais próximos uns dos outros.

Há ainda a questão do desemprego, das políticas neoliberais adotadas pelo atual governo que retira do Estado a responsabilidade de promover políticas de bem-estar social, principalmente as populações mais vulneráveis, como é o caso das favelas. (KOWARIC, 2009).

Tais políticas utilizam uma lógica baseada na ideia de que alguém vale mais do que outro. Isso pode ser notado nos pronunciamentos do presidente que sugerem que a perda de algumas vidas é aceitável para não parar a economia. Nesse discurso, percebe-se nitidamente que na concepção do presidente, algumas vidas são mais descartáveis do que outras. O governante, ao fazer essas afirmações, age como o soberano, pois não considera os direitos fundamentais e a dignidade humana dessas vidas. São vidas desqualificadas, que não merecem viver. Nessa perspectiva, o governante, como expressão máxima de soberania e poder, goza da capacidade de decidir quais vidas são merecedoras de continuarem sendo vividas. (AGAMBEN, 2004). O favelado encarna a vida do o homo sacer, ele aparece como a inserção da vida desqualificada no campo da política, como parte de seu alvo, porém, não para receber investimento, mas abandono. O favelado, por viver em áreas de abandono aparece como a vida nua exposta à morte. (DUARTE, 2010, p. 284).

Endo (2005) ressalta que os territórios de exclusão, como as favelas, representam um desenho urbanístico injusto e desigual das cidades. $O$ autor aponta que algumas áreas são reservadas aos mais pobres, ao mesmo tempo em que em outras áreas são habitadas 
por pessoas que possuem melhores condições econômicas, isso pode atenuar ou agravar o risco de pessoas contraírem algum tipo de doença.

A exposição diferencial dos seres humanos a riscos de saúde e riscos sociais é, segundo Foucault (2005), um traço marcante da biopolítica. Para pensar essa diferença o autor evoca a questão do racismo de Estado. Com a emergência da biopolítica, o racismo torna-se o meio de fragmentar o continuum biológico a fim de criar hierarquias entre diferentes grupos humanos e, portanto, diferenças radicais na maneira como eles são expostos ao risco de morte. Em suma, a biopolítica é sempre uma política que depende estruturalmente do estabelecimento de hierarquias no valor das vidas, produzindo e multiplicando a vulnerabilidade como meio de governar pessoas.

O abandono das favelas por parte do poder Estatal faz com esses espaços se tornem regiões muito afetadas pela pandemia do coronavírus, isso ocorre devido à omissão e o abandono. Um fato que explicita esse abandono são as ações que estão sendo tomadas pelos próprios trabalhadores em relação à prevenção do coronavírus. Essas ações se baseiam em algumas frentes como o compartilhamento e coleta de informações; recolhimento de doações para compra de alimentação e materiais de limpeza; medidas educativas sobre a importância do racionamento de água; monitoramento de pessoas que são consideradas do grupo de risco.

Um exemplo dessas ações vem ocorrendo em comunidades como o Complexo do Alemão, que criou um gabinete de crise na comunidade e que tem por objetivo conscientizar a população, buscar recursos para o enfrentamento à pandemia e pressionar para que os governantes atuem nas favelas e viabilizem condições básicas para a prevenção. Em Manguinhos, o Fórum Social de Manguinhos e as Mães de Manguinhos lançaram campanha em suas redes sociais para recebimento de cestas básicas e kits de limpeza, como forma de colaboração com moradores que se encontram desempregados e em situação de vulnerabilidade.

Na maior parte das favelas, os próprios moradores estão fazendo um monitoramento dos idosos e suas necessidades, para que os mesmos não precisem sair de casa. Voluntários e coletivos estão em constante contato com as unidades de saúde para atualização de informações e medidas que possam ser tomadas para a prevenção. Apesar das dificuldades 
de acesso à internet que a população enfrenta, as redes sociais tem sido um importante instrumento para o combate a pandemia. (EQUIPE FASE RIO DE JANEIRO, 2020).

Segundo Blois (2020), outra prática observada nas favelas diz respeito às ações que vem sendo tomadas pelo próprio tráfico que passou a adotar toques de recolher com altofalantes (em carros e postes). Eles avisam aos moradores que eles estão proibidos de circular e em caso de desrespeito, podem ser punidos. O domínio por um poder paralelo e a relação de abandono por parte do Estado explicita claramente que a exceção é a regra nas favelas. Nas favelas, há um espaço de exceção ao ordenamento jurídico, onde a vida nua se encontra em sua máxima exposição e, desse modo, à completa sujeição ao Estado. (YAMAMOTO, 2017).

O Estado ao romper com o pacto que tem com a população acaba sujeitando a mesma a todo tipo de privação de direitos. A vida nua fica circunscrita aos bolsões de pobreza existentes nas favelas. (YAMAMOTO, 2017). Esses bolsões se traduzem na noção agambeniana de bando, um termo que remete a aqueles que foram banidos, os excluídos, ou seja, os indivíduos que estão, ao mesmo tempo, numa relação de pertencimento e exclusão. (AGAMBEN, 2004)

Nesse sentido, o bando se apresenta como a forma em que o poder soberano organiza os corpos. Fora de qualquer jurisdição sem nenhum direito, ao abandonado resta apenas a vida sem valor. Nesse ponto, é importante consignar que, eliminar a vida não se compreende, na perspectiva foucaultiana, unicamente o assassínio direto, mas também tudo que pode ser considerado assassínio indireto: "o fato de expor à morte, de multiplicar para alguns o risco de morte ou, pura e simplesmente, a morte política, a expulsão, a rejeição". (FOUCAULT, 2005, p. 306). O racismo de Estado se coloca como um aspecto determinante no processo de definição das condições de aceitabilidade para quem vive e morre, no sentido de que a vida do pobre é colocada no topo da lista daqueles que serão descartados pelo Estado. (FOUCAULT, 2005).

Nas favelas do Rio e da Baixada Fluminense, a omissão e o abandono do Estado é tão grande que as medidas de prevenção estão sendo tomadas pelos próprios moradores das comunidades que passaram a se articular para pensar em soluções de acordo com suas necessidades específicas. Outra prática observada nas favelas diz respeito a traficantes de 
drogas que ordenam toques de recolher com alto-falantes (em carros e postes) e batem às portas das casas para avisar aos moradores que eles estão proibidos de circular. Eles deixam claro aos moradores que em caso de desrespeito as ordens, eles serão punidos. O domínio por um poder paralelo e a relação de abandono por parte do Estado explicita claramente que a exceção é a regra nas favelas. Conforme aponta Yamamoto (2017, p. 51), "nas favelas, há um espaço de exceção ao ordenamento jurídico, onde a vida nua se encontra em sua máxima exposição e, desse modo, à completa sujeição ao Estado".

Em países como EUA, China e Alemanha, cuja economia é mais sólida, as autoridades estão conseguindo se manter em isolamento e receber o tratamento adequado. Esses países já anunciaram incentivos financeiros na casa de trilhões de dólares para manter a atividade produtiva. Assim, o número de casos nesses países deve atingir um pico e depois se normalizar.

Contudo, essa não é uma alternativa para as comunidades mais pobres que dependem de transporte público, não tem poupanças, não podem comprar produtos de higiene, moram com famílias grandes e devem continuar trabalhando. É preciso lembrar que boa parte dessa população vive e trabalha em condição de total informalidade, ou seja, o afastamento do trabalho implica na não remuneração. (HARVEY, 2020). O autor questiona a eficácia de medidas como o fechamento de cidades na contenção, conforme diretrizes da Organização Mundial da Saúde (OMS) sobre isolamento de doentes. Para ele, as recomendações não levam em conta a realidade desigual dos países. Harvey (2020) afirma ainda que se analisarmos as recomendações da OMS de quarentena, chegaremos a conclusão de que elas são pouco factíveis para países pobres.

A questão mais preocupante, e para a qual temos poucos dados, é saber como se dará a evolução de Covid-19 numa população que vive em condições precárias e que terá dificuldade de executar de forma apropriada as recomendações de isolamento social e de higiene. Somente quando a transmissão de Covid-19 atingir o seu pico, é que poderemos avaliar de forma mais objetiva qual será o seu Impacto sobre os moradores das favelas. 


\section{CONSIDERAÇÕES FINAIS}

O estado de exceção revela-se como regra nas favelas, na medida em que a população vive em uma zona de indeterminação. Nessa zona, é possível observar que os excluídos sociais que sobrevivem, apesar de não terem acesso aos direitos fundamentais, valem-se do estado de exceção cotidiano. Em outras palavras, vigora sobre suas vidas a suspensão dos direitos fundamentais, o que torna a vida deles vulnerável. Essa situação de se agrava ainda mais no contexto de uma pandemia.

É importante ressaltar que muito antes que a epidemia da Covid-19 chegasse às favelas e periferias a situação da precariedade dos serviços de saúde que atendem estas localidades já era uma realidade. Favelas e periferias vêm enfrentando a pandemia em condições mais adversas, decorrentes do descaso dos governos em prover condições adequadas de saúde a essa população. Não se trata mais de falar na ausência de políticas públicas para esses territórios, mas de uma forma de exclusão promovida pelo Estado.

O poder biopolítico estabelece hierarquias e separações e molda as desigualdades, construindo mecanismos que despojam certos grupos de sua humanidade, o que implica em fazer sobre a população uma série de cortes e limites que fixam o que é e o que não é humano, caracterizando indivíduos e grupos e, por conseguinte, a relação deles a exceção. Nas favelas, vivencia-se o espaço de exclusão, no qual a vida nua é incluída e capturada. A pandemia da Covid-19, portanto, tem deixado ainda mais visível a faceta cruel de viver em territórios tão desiguais.

\section{REFERÊNCIAS}

AGAMBEN, Giorgio. Homo sacer: o poder soberano e a vida nua. Tradução: Henrique Burigo. Belo Horizonte: Editora da UFMG, 2004.

ALFANO, Bruno; COSTA, Célia; Leão, Ana Letícia; MARTINS, Elisa; MENDES, ALESSANDRA. Coronavírus: aglomerações e sistemas de saúde de metrópoles brasileiras preocupam autoridades. O Globo, 15 de março de 2020. Disponível em: https://oglobo.globo.com/sociedade/coronavirus/coronavirus-aglomeracoes-sistemas-desaude-de-metropoles-brasileiras-preocupam-autoridades24306046?utm_campaign=compartilhar\&utm_medium=Social\&utm_source=Twitter. Acesso em: 20 abr. 2020. 
AGAMBEN, Giorgio. Estado de Exceção. Tradução: Iraci Poleti. São Paulo: Boitempo, 2002.

BARRUCHO, Luis. 'Pula no esgoto e nada acontece': Brasil tem mais de 300 mil internações por ano por doenças causadas por falta de saneamento. BBC NEWS: BRASIL, 27 de março de 2020. Disponível em: https://www.bbc.com/portuguese/geral-52067247. Acesso em: 20 abr. 2020.

BLOIS, Caio. Tráfico impõe toque de recolher em favelas do Rio em meio a crise do corona. UOL, 24 de março de 2020. Disponível em: https://noticias.uol.com.br/cotidiano/ultimasnoticias/2020/03/24/coronavirus-faccoes-do-trafico-impoem-toque-de-recolher-em-favelasdo-rj.htm?cmpid=copiaecola. Acesso em: 20 abr. 2020.

DREYFUSS, Hubert; RABINOW, Paul. Beyond structuralism and hermeneutics. Brighton: The Harvester Press, 2006.

EQUIPE FASE RIO DE JANEIRO. Covid-19 escancara a injustiça da vida nas favelas e periferias. Fase, 31 de março de 2020. Disponível em: https://fase.org.br/pt/informe-se/artigos/covid19-escancara-a-injustica-da-vida-nas-favelas-e-periferias/. Acesso em: 20 abr. 2020.

DUARTE, André. Vidas em risco: crítica do presente em Heidegger, Arendt e Foucault. Rio de Janeiro: Forense Universitária, 2010.

ENDO, Paulo Cesar. A violência no coração da cidade: um estudo psicanalítico. São Paulo, Escuta/Fapesp, 2005.

FOUCAULT, Michel. História da sexualidade 1: a vontade de saber. Rio de Janeiro: Graal, 2005.

GIRARDI, Giovana. OMS declara pandemia de novo coronavírus. Estadão, 11 de março de 2020. Disponível em: https://saude.estadao.com.br/noticias/geral,oms-declara-pandemiade-novo-coronavirus-mais-de-118-mil-casos-foram-registrados,70003228725. Acesso em: 20 abr. 2020.

HARVEY, David. Política anticapitalista em tempos de COVID-19. In: DAVIS, Mike; ŽIŽEK, Slavoj; BADIOU Alain; DAVIS, Mike; BIHR, Alain; ZIBECHI, Raúl. Coronavírus e a luta de classes. Brasil: Terra sem Amos, 2020.

IBGE. Censo 2010. Disponível em: https://censo2010.ibge.gov.br/resultados.html. Acesso em: 27 abr. 2020.

FARIAS, Juliana. Quando a exceção vira regra: os favelados como população "matável" e sua luta por sobrevivência. Teoria \& Sociedade, Belo Horizonte, n. 15, p. 138-171, jul./dez. 2008. Disponível em: https://edisciplinas.usp.br/pluginfile.php/4905896/mod_resource/content/1/artigo\%20\%20Quando\%20a\%20exce\%C3\%A7\%C3\%A30\%20vira\%20regra- 
\%20os\%20favelados\%20como\%20popula\%C3\%A7\%C3\%A3o\%20mat\%C3\%A1vel\%20e\%20su a\%20luta\%20por\%20sobreviv\%C3\%AAncia.pdf. Acesso em: 31 mar. 2020.

KOWARICK, Lúcio. Viver em risco: sobre a vulnerabilidade socioeconômica e civil. São Paulo: Editora 34, 2009.

LING, Anthony. Epidemias: o fracasso das cidades? Caos Planejado, 18 de março de 2020. Disponível em: https://caosplanejado.com/epidemias-o-ponto-fraco-de-grandes-cidades/. Acesso em: 31 mar. 2020.

RIO DE JANEIRO (Estado). Secretaria Municipal de Urbanismo. Os dados mais recentes sobre a população de favelas na cidade do Rio de Janeiro. Coleção Estudos Cariocas, Rio de Janeiro, 2010.

ROLNIK, R. Exclusão territorial e violência. São Paulo em Perspectiva, São Paulo, v. 13, n. 4, p. 100-111, out./dez. 1999. Disponível em: https://www.scielo.br/scielo.php?script=sci_arttext\&pid=S0102-88391999000400011. Acesso em: 31 mar. 2020.

YAMAMOTO, E. Y. Favela, comunidade e comunidade-que-vem. In: PILATTI, Adriano; MATOS, Andityas Soares de Moura Costa. CORRÊA; Murilo Duarte Costa. (org). 0 estado de exceção e as formas jurídicas. Ponta Grossa: UEPG, 2017. p. 43-75.

Recebido em 28/04/2020.

Aceito em 25/05/2020. 